\title{
KAJIAN DAERAH TERINTRUSI AIR LAUT DI WILAYAH PESISIR KECAMATAN KUTA UTARA, KABUPATEN BADUNG
}

\author{
I Made Sukearsana ${ }^{1 *)}$, I Gusti Bagus Sila Dharma ${ }^{2)}$, I Wayan Nuarsa ${ }^{3)}$ \\ ${ }^{1)}$ Dinas Cipta Karya Kabupaten Badung \\ ${ }^{2}$ Fakultas Perikanan dan Kelautan Universitas Udayana \\ ${ }^{3)}$ Program Studi Magister Ilmu Lingkungan Universitas Udayana \\ ${ }^{*}$ Email : madesukearsana@gmail.com
}

\begin{abstract}
The total population of District Kuta Utara 2014 recorded 68.422 people with an average population density of 2,021 people $/ \mathrm{km}^{2}$ while the number of tourism accommodation facilities (hotels, villas, restaurants) recorded 399 pieces. The rapid of population growth and the development of tourism accommodation facilities require ground water more increasing. Intake of large amounts of ground water potential to cause pollution/ sea water intrusion. This study aims to determine the quality of the groundwater, knowing distribution maps sea water intrusion and to predict the level of sea water intrusion coming years.

This research method uses descriptive quantitative method. Furthermore, to determine the quantity and quality of ground water was measured groundwater levels and analysis of the parameters of temperature, total dissolved solid, $\mathrm{pH}$, chloride, hardness and electrical conductivity of the 60 sample wells. Results of analysis of each of the key parameters that can be mapped and known overlay distribution maps sea water intruded area.

The observation of the quantity and quality of groundwater in coastal areas of Kuta Utara subdistrict shows the range of the depth of the ground water level between -5.15 meters to -22.16 meters. Results of the analysis of ground water quality of the 60 groundwater samples showed that there has been a decline in the quality of ground water is as much as 14 samples total dissolved solid (TDS) the highest reaches $1,122 \mathrm{mg} /$ l, the highest electrical conductivity reached 1,677 iMhos / cm and the highest chloride reached $532,5 \mathrm{mg} / \mathrm{l}$. Distribution maps sea water intruded area shows that in coastal areas troubled district of Kuta Utara indicated seawater intrusion, especially in the area of Petitenget and Batubelig, Kerobokan Kelod Village area of $78.44 \mathrm{Ha}$. Prediction of sea water intrusion in 2022 was highest in the area of tourism accommodation caused by ground water extraction enough much, kind of gray-brown soil regosol has a rough texture and high permeability characteristics so it is easy to pass groundwater.
\end{abstract}

Keywords: Underground water; quality of underground water, seawater intrusion, Kuta Utara District

\section{PENDAHULUAN}

Air diperlukan manusia untuk memenuhi berbagai macam kebutuhan hidup. Pemanfaatannya tidak sekedar hanya untuk keperluan air rumah tangga, tetapi diperlukan untuk semua sektor yaitu sektor industri, perdagangan, pertanian, kesehatan, pendidikan, perkantoran dan sektor pariwisata. Air bahkan sudah merupakan komoditas yang diperdagangkan, tidak terbatas untuk memenuhi kebutuhan dalam negeri, tetapi juga diekspor ke negara lain untuk memperoleh keuntungan ekonomi (Danaryanto, dkk. 2005).

Purwanto (2003), menyatakan kurang lebih 80\% penduduk Indonesia memanfaatkan air tanah sebagai sumber air bersih untuk kehidupan sehari hari baik di daerah perkotaan maupun di daerah pedesaan. Sedangkan laporan Bank Dunia tahun 1983 menyatakan bahwa sebagian besar kebutuhan air bersih bagi keperluan domestik rumah tangga dan industri diperoleh dari sumber air tanah yaitu $57 \%$, dari mata air $16 \%$ dan dari perusahaan air minum hanya 6,5\% (Ashriyati, 2011).

Perda Kabupaten Badung Nomor 26 Tahun 2013 tentang Rencana Tata Ruang Wilayah Kabupaten Badung, menyebutkan bahwa Kecamatan Kuta Uatara sebagai Pusat Kawasan Perkotaan dan sebagian wilayah pesisirnya termasuk dalam Kawasan Pariwisata. Laporan Dinas Pendapatan Daerah (2013), menyebutkan jumlah akomodasi dan fasilitas penunjang pariwisata (hotel bintang/ non bintang, pondok wisata/ villa, rumah kost, restoran dan rumah makan) di Kecamatan Kuta Utara mencapai 399 buah.

Nurrohim, dkk. (2012), mengatakan faktor faktor yang mempengaruhi intrusi air laut adalah kondisi geologi pada material alluvium, kondisi geohidrologi pada akuifer dangkal dengan produktifitas sedang, kondisi penggunaan lahan dan daerah dengan kepadatan penduduk yang tinggi. Permasalahan yang dapat dirumuskan dalam penelitian ini adalah : bagaimanakah kualitas air 
tanah saat ini, sejauhmana intrusi air laut telah terjadi dan bagaimana prediksi penyebaran intrusi air laut di wilayah pesisir Kecamatan Kuta Utara pada tahun 2022.Adapun tujuan dari penelitian ini adalah untuk menentukan kualitas air tanah, membuat peta sebaran intrusi air laut dan memprediksi tingkat intrusi air laut beberapa tahun kedepan di wilayah pesisir Kecamatan Kuta Utara.

\section{METODOLOGI}

Rancangan penelitian ini menggunakan metoda diskriptif kuantitatif. Secara administratif lokasi penelitian terletak di wilayah pesisir Kecamatan Kuta Utara meliputi Kelurahan/ desa Kerobokan Kelod, Kerobokan, Tibu Beneng dan Canggu Kecamatan Kuta Utara, Kabupaten Badung, Propinsi Bali.

\subsection{Variabel Penelitian}

Adapun variabel penelitian dalam pelaksanaan kajian daerah terintrusi air laut di wilayah pesisir Kecamatan Kuta Utara meliputi :

a. Kualitas air tanah

Untuk mendapatkan kualitas air tanah guna mengetahui terindikasinya intrusi air laut dilakukan analisa terhadap parameter kunci seperti sifat fisika : tempratur (suhu) dan jumlah zat padat terlarur. Sifat kimia parameternya yaitu derajat keasaman $(\mathrm{pH})$, klorida dan daya hantar listrik (Armadi, 2005).

b. Tinggi muka air tanah dan arah aliran air tanah dilaksanakan dengan pengukuran kedalaman muka air tanah pada masing masing sumur di daerah penelitian.

c. Selain itu perlu dilakukan interpretasi terhadap peta geologi, hidrogeologi untuk mengetahui jenis batuan daerah penelitian, peta tata guna lahan untuk mengetahui penggunaan lahannya, peta administrasi untuk mengetahui luas wilayah per desa serta peta demografi untuk mengetahui jumlah sebaran penduduk.

\subsection{Prosedur Penelitian}

Dalam melaksanakan penelitian di wilayah pesisir Kecamatan Kuta Utara dilakukan tahapan prosedur penelitian sebagai berikut:

\subsubsection{Penentuan Sampel}

Pengambilan sampel dilakukan dengan terlebih dahulu menentukan unit lahan dengan tujuan untuk stratifikasi pengambilan sampel. Unit lahan dibentuk dari kompilasi peta penggunaan lahan, peta geologi, peta hidrogeologi dan peta jenis tanah. Jumlah sampel yang diambil sebanyak 60 sampel. Berdasarkan kompilasi peta peta tersebut dihasilkan 5 (lima) kelompok unit lahan dengan luas keseluruhan 2.241 Ha, sebagai berikut : kawasan akomodasi pariwisata dengan jenis tanah latosol coklat seluas 58,6 Ha sebanyak 4 sampel, kawasan akomodasi pariwisata jenis tanah regosol coklat kelabu seluas 291,4 Ha sebanyak 12 sampel, kawasan sempadan sungai seluas $376,6 \mathrm{Ha}$ sebanyak 13 sampel, kawasan pemukiman seluas 946,1 Ha sebanyak 23 sampel dan kawasan lahan basah seluas 568,3 Ha sebanyak 8 sampel.

\subsubsection{Penentuan Kualitas Air Tanah}

Dalam menentukan kualitas air tanah dan arah aliran air tanah di daerah penelitian dilakukan tahapan sebagai berikut:

a. Pengambilan data primer berupa sampel air tanah (air sumur bor/ sumur gali) dan tinggi muka air tanah. Sampel air diambil sebanyak 1 (satu) liter kemudian ditampung pada sebuah botol plastik. Guna mengetahui kualitas air sumur yang meliputi parameter yaitu suhu, total dissolved solid (TDS) dan daya hantar listrik (DHL) diukur secara langsung di lapangan dengan alat yang sudah disiapkan.

b. Melaksanakan pengukuran tinggi muka air tanah (MAT) masing masing sampel sumur bor/ gali yang diukur secara langsung di lapangan dengan menggunakan alat water level meter.

c. Melaksanakan analisa fisika dan kimia di UPT. Laboratorium Kesehatan Propinsi Bali di Denpasar terhadap parameter fisika yaitu suhu dan TDS serta parameter kimia yaitu pH, DHL, khlorida $(\mathrm{Cl})$ dan kesadahan $\left(\mathrm{CaCo}_{3}\right)$.

d. Mengumpulkan data skunder dari berbagai sumber antara lain :data Iklim (curah hujan, suhu dan kelembaban), jumlah sumur produksi, jumlah pemakaian air tanah, data sosial ekonomi meliputi demografi, mata pencaharian dan pendapatan, jumlah penduduk, tenaga kerja dan kelembagaan masyarakat

e. Melakukan pengolahan dan analisa data terhadap data dan peta yang sudah tersedia dengan jalan merumuskan, menulis dan memetakan apa yang didapatkan sesuai kerangka penelitian yang telah ditentukan.

f. Selanjutnya hasil pengolahan data dan pemetaan tersebut juga dilakukan interpretasi maupun kajian untuk mengetahui sebaran intrusi air laut saat ini dan prediksi sebaran intrusi air laut pada tahun tahun mendatang.

\subsection{Analisis Data}

\subsubsection{Analisis Data Kualitas dan Kuantitas Air Tanah}

Analisis data kualitas air tanah hasil penelitian ini dilakukan melalui beberapa tahap :

a. Hasil pemeriksaan parameter kualitas air tanah dianalisis secara diskriptif dan dibandingkan dengan baku mutu air Kelas I (air yang dapat 
digunakan sebagai air baku untuk air minum) sesuai Pergub Bali Nomor 8 tahun 2007

b. Setelah diketahui hasil analisa 6 (enam) parameter kunci yang kuat mempengaruhi instrusi air laut seperti suhu, TDS, pH, DHL, Cl dan kesadahan dibuatkan peta parameter kunci dan dilakukan overlay untuk mengetahui terjadinya intrusi air laut.

c. Tingkat penurunan kondisi air tanah secara kuantitas di daerah penelitian dibandingkan dengan tabel tingkat kerusakan kondisi air.

\subsubsection{Analisis Prediksi Sebaran Daerah Terintrusi Air Laut}

Analisis statistika yang digunakan untuk melihat hubungan antara dua atau lebih variabel yang saling berkorelasi di wilayah pesisir Kecamatan Kuta Utara adalah analisis regresi linier sederhana (simple linier regression). Data yang diperlukan dalam menganalisis prediksi sebaran daerah terintrusi air laut adalah data analisa fisika kimia air tanah sumur produksi yang ada di wilayah penelitian tahun 2001, 2008 dan tahun 2015, menyiapkan peta daerah terintrusi air laut eksisting sebagai acuan dalam memprediksi sebaran daerah terintrusi air laut.dan menyiapkan data muka air tanah beberapa sumur produksi maupun sumur pantau tahun 2001, 2008 dan tahun 2015.

\subsubsection{Pembuatan Peta Muka Air Tanah dan Peta Sebaran Intrusi Air Laut}

Pembuatan peta kedudukan tinggi muka air tanah, arah aliran air tanah dan peta sebaran daerah terintrusi air laut dilaksanakan degan urutan kerja yaitu menentukan titik koordinat geografis lokasi sampel dan memetakan ke dalam peta dasar digital, melakukan interpolasi data terhadap tinggi muka air tanah maupun parameter kunci yang mempengaruhi intrusi air laut dari masing masing sampel yang sudah ditentukan titik koordinatnya, membuat peta tematik kondisi saat ini yaitu peta sebaran suhu, TDS, pH, DHL, Cl, $\mathrm{CaCo}_{3}$ dan peta daerah terintrusi air laut serta peta kedudukan muka air tanah maupun peta arah aliran air tanah dan melakukan analisis dan estimasi beberapa tahun ke depan untuk menghasilkan peta prediksi intrusi air laut di masa mendatang.

\section{HASIL DAN PEMBAHASAN}

Kecamatan Kuta Utara merupakan salah satu Kecamatan di Kabupaten Badung, Propinsi Bali terletak pada posisi geografis $8^{\circ} 37^{\prime} 07.2^{\prime \prime} \mathrm{LS}$ $8^{\circ} 41^{\prime} 01.8^{\prime \prime} \mathrm{LS}$ dan $115^{\circ} 07^{\prime} 18.3^{\prime \prime}$ BT - 115¹0'56.9" BT.. Batas administrasi wilayah Kecamatan Kuta Utara adalah di sebelah Utara berbatasan dengan Kecamatan Mengwi, di sebelah Selatan berbatasan dengan Kecamatan Kuta, di sebelah Timur berbatasan dengan Kota Denpasar dan di sebelah Barat berbatasan dengan Samudera Hindia.

Struktur geologi Kecamatan Kuta Utara sebagian besar merupakan produk gunung api muda yang terdiri dari breksi vulkanik, tufa pasiran dan endapan lahar (Hadiwidjojo, 1986). Sebagian kecil daerah pesisir sekitarnya merupakan daerah alluvial endapan pantai yang tersusun dari pasir. Pada umumnya di Kecamatan Kuta Utara jenis batuan yang ada berupa tufa ( Qpbb), berwarna abu - abu kehitaman, berukuran pasir halus - sedang, porous dan agak keras. ataupun urutan stratigrafi daerah penyelidikan yaitu keterdapatan batuan seperti pasir, kerakal, kerikil serta lempung dan lanau dapat memperkirakan lapisan yang kedap air, akuifug dan akuifer. Berdasarkan Peta Tinjau Hidrogeologi Kabupaten Badung (Djaeni A. 1982) kandungan air tanah di daerah Kecamatan Kuta Utara di kelompokkan menjadi 3 yaitu : kandungan air sedang dengan debit 5 lt/det, kandungan air kurang dengan debit 5 lt/det, kandungan air sangat sedikit sekali dengan debit < 0,1 lt/det dan daerah terpengaruh oleh air laut di Kecamatan Kuta Utara.

Kebutuhan air tanah di wilayah pesisir Kecamatan Kuta Utara terus mengalami peningkatan guna memenuhi kebutuhan rumah tangga maupun jasa usaha pariwisata. Jumlah penduduk Kecamatan Kuta Utara Tahun 2014 tercatat 68.422 jiwa dengan kepadatan penduduk rata rata 2.021 jiwa $/ \mathrm{km}^{2}$ sedangkan jumlah sarana akomodasi pariwisata (hotel, villa, restoran) tercatat 399 buah. Cakupan pemenuhan air bersih melalui Perusahaan Daerah Air Minum (PDAM) Tirta Mangutama Kabupaten Badung baru mencapai $53,40 \%$.

\subsection{Kedalaman Muka Air Tanah dan Arah Aliran Air Tanah}

Pengamatan muka air tanah di daerah penelitian dilakukan terhadap 60 sampel sumur. Hasil pengamatan tinggi muka air tanah menunjukkan penurunan muka air tanah secara signifikan dari tahun ke tahun. Dari hasil pengukuran yang dilakukan terhadap kedalaman muka air tanah sumur menunjukkan kisaran kedalaman yang bervariasi pada setiap sampel dan pada masing masing kawasan penggunaan lahan. Muka air tanah (MAT) terdangkal adalah 5,15 meter terletak di Banjar Batu Belig, Kerobokan Kelod dan muka air tanah (MAT) paling dalam adalah 22,16 meter terdapat di Banjar Padang Tawang desa Canggu. Keadaan tinggi muka air tanah di wilayah pesisir Kecamatan Kuta Utara seperti disajikan dalam Gambar 1.

Hasil pengukuran elevasi sumur di daerah penelitian menunjukkan kisaran elevasi sumur 11,0 - 46,0 meter di atas permukaan laut Gambar 2, 




Gambar 1. Keadaan Tinggi Muka Air Tanah di wilayah Pesisir Kec. Kuta Utara

menunjukkan bahwa tinggi muka air tanah masih di atas permukaan air laut yaitu 1,84 - 23,84 meter di atas muka air laut Arah aliran air tanah di wilayah pesisir Kecamatan Kuta Utara mengikuti arah kemiringan lahan. Gambar 2 menunjukkan arah aliran air tanah yang mengikuti ketinggian muka air tanah di atas permukaan laut yang dibagi ke dalam 5 klasifikasi yaitu ketinggian antara $0-$ 4,9 meter, 5-9,9 meter, 10 - 14,9 meter, 15 - 19,9 meter dan 20-24,9 meter. Berdasarkan ketinggian muka air tanah tersebut dapat diketahui bahwa aliran air tanah menuju laut ke arah pantai Selatan sebagaimana Gambar 2.

Kualitas air tanah khususnya untuk bahan baku air minum dan keperluan rumah tangga seperti mandi, masak, cuci dan kakus, secara idealnya harus memenuhi standar mutu yang baik. Dalam menentukan standar kualitas air dapat diukur dengan menentukan parameter fisik, kimia, dan

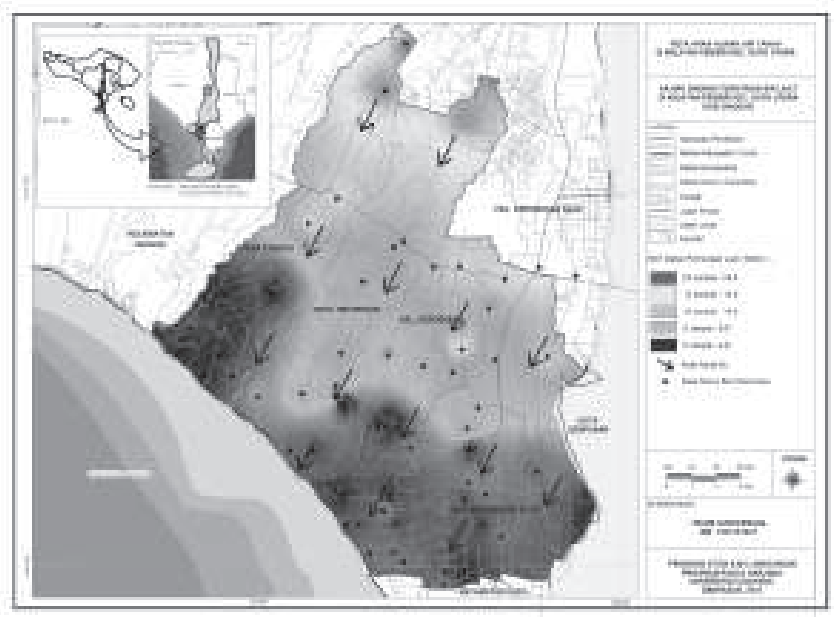

Gambar 2. Arah Aliran Air Tanah di wilayah Pesisir Kec. Kuta Utara mikrobiologi air (Effendi, 2003). Apabila kualitas air yang diukur melampaui ambang batas maksimum yang diperbolehkan berdasarkan standar yang ditentukan atau berdasarkan peraturan pemerintah, maka kualitas air tersebut menurun sesuai peruntukannya, sehingga digolongkan sebagai air yang tercemar (Fardiaz, 1992).

\subsection{Sebaran Daerah Terintrusi Air Laut}

Pelaku pariwisata maupun masyarakat yang ada di wilayah pesisir Kecamatan Kuta Utara lebih banyak memanfaatkan air tanah untuk kebutuhan hotel maupun keperluan domestik rumah tangga. Pemanfaatan air tanah yang digunakan untuk keperluan sehari-hari harus memenuhi kualitas air tanah berdasarkan baku mutu air yang tertuang dalam Pergub. Bali Nomor 8 Tahun 2007 tentang Baku Mutu Lingkungan Hidup dan Kriteria Baku Kerusakan Lingkungan Hidup untuk air golongan kelas I. Rata rata hasil pengamatan sampel air tanah sumur bor/ gali yang ada di wilayah penelitian dapat diklasifikasikan untuk masing masing kawasan penggunaan lahan sebagaimana tabel 1

Untuk mengetahui sejauh mana intrusi air laut telah terjadi, dilakukan perhitungan dengan mengkompilasi (overlay) hasil pengamatan maupun analisa fisika dan kimia air tanah terhadap parameter total dissolved solid (TDS), suhu, clorida, $\mathrm{pH}$ dan daya hantar listrik (DHL). Hasil analisis kualitas air tanah terhadap 60 sampel menunjukkan bahwa telah terjadi penurunan kualitas air tanah sebanyak 14 sampel yaitu total dissolved solid (TDS) tertinggi mencapai $1.122 \mathrm{mg} / \mathrm{l}$, daya hantar listrik tertinggi mencapai $1.677 \mu \mathrm{Mhos} / \mathrm{cm}$ dan khlorida tertinggi mencapai $532,5 \mathrm{mg} / \mathrm{l}$. Tingginya konsentrasi TDS, khlorida dan DHL yang mengakibatkan terjadinya intrusi air laut di beberapa titik sumur disebabkan karena sebagian besar hotel hotel menggunakan air tanah. Selain itu, jenis tanah yang ada di kawasan akomodasi pariwisata berdasarkan peta jenis tanah Kecamatan Kuta Utara adalah regosol coklat kelabu yang memiliki karakteristik bertekstur kasar dan permeabilitasnya tinggi sehingga mudah meloloskan air (Santoso dkk, 2013).

Apabila diamati sumur yang telah mengalami intrusi air laut terjadi pada lokasi pengambilan air tanahnya tinggi yaitu di Hotel Intan Beach Village/ Hotel W, Koena Koeni Villa, Ailla Seminyak Bali, Lega Vila dan Puri Bidadari Hotel serta Bali Sani Suite Hotel dengan rata rata pemakaian air tanah perbulan mencapai $4.846 \mathrm{~m}^{3} /$ bulan. Disamping itu keadaan geologi di kawasan akomodasi pariwisata merupakan daerah alluvium dimana bahan induknya berupa kerikil pasir, lanau dan lempung sebagai endapan sungai dan pantai yang rentan terhadap air laut. Peta sebaran daerah teintrusi air laut menunjukkan bahwa telah terindikasi rawan intrusi air laut terutama di daerah Petitenget dan 
Tabel 1. Rata Rata Hasil Pengukuran Sampel Air Sumur masing masing Unit Lahan

\begin{tabular}{|c|c|c|c|c|c|c|c|c|}
\hline \multirow{2}{*}{ No } & \multirow{2}{*}{ PARAMETER } & \multirow{2}{*}{ SATU AN } & \multirow{2}{*}{ BAKU MUTU } & \multicolumn{5}{|c|}{ LOKASI SAMPEL } \\
\hline & & & & I & II & III & IV & V \\
\hline 1 & $\begin{array}{l}\text { Jumlah Zat Padat } \\
\text { terlarut(TDS) }\end{array}$ & $M g / l$ & 1.000 & 540.7 & 850.50 & 549.61 & 623.47 & 500.4 \\
\hline 2 & Suhu & ${ }^{\circ} \mathrm{C}$ & $\pm 3^{\circ} \mathrm{C}$ & 26.72 & 27.49 & 27.25 & 27.44 & 27.56 \\
\hline 3 & Kesadahan (CaCo3) & Mg/l & 500 & 347.3 & 328.5 & 255.97 & 299.35 & 291.4 \\
\hline 4 & Klorida $(\mathrm{Cl})$ & $\mathrm{Mg} / \mathrm{l}$ & 600 & 37.01 & 94.38 & 49.17 & 70.52 & 37.05 \\
\hline 5 & $\mathrm{pH}$ & - & $6-9$ & 7.00 & 7.03 & 7.13 & 6.98 & 6.98 \\
\hline 6 & $\mathrm{DHL}$ & UMhos/ cm & 1.000 & 813.0 & 1,158 & 803.84 & 808.38 & 750.9 \\
\hline
\end{tabular}

Keterangan:

$\mathrm{I}=$ Kawasan akomodasi pariwisata dengan jenis tanah latosol coklat

II = Kawasan akomodasi pariwisata dengan jenis tanah regosol coklat kelabu

III = Kawasan sempadan sungai

IV = Kawasan pemukiman

$\mathrm{V}=$ Kawasan lahan basah

Batu Belig, Kelurahan Kerobokan Kelod seluas 78,44 Ha. Secara rinci peta daerah terintrusi air laut di wilayah pesisir Kecamatan Kuta Utara dapat dilihat pada Gambar 3.

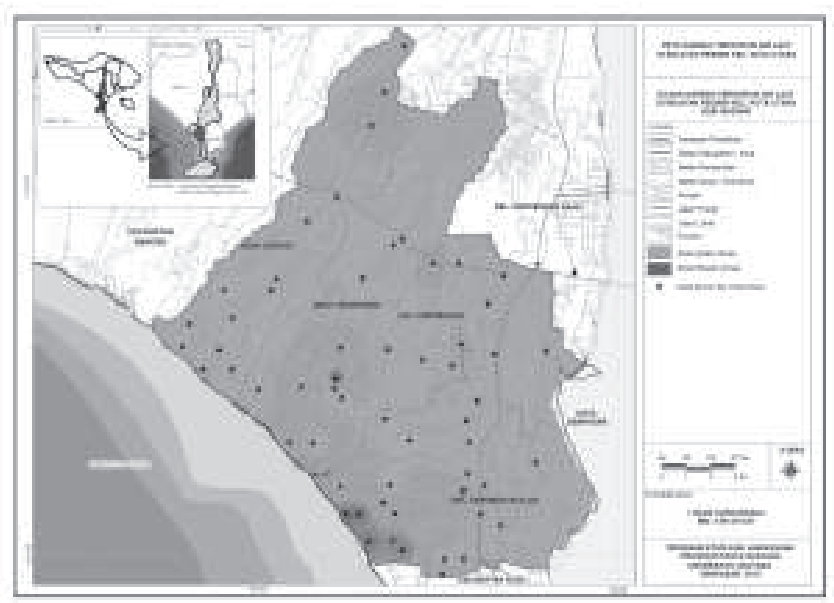

Gambar 3. Peta Daerah Terintrusi Air Laut di Wilayah Pesisir Kec. Kuta Utara

\subsection{Prediksi Penurunan Muka Air Tanah}

Untuk mengetahui kemungkinan semakin menurunnya tinggi muka air tanah dilakukan perhitungan analisis pendugaan penurunan muka air tanah dengan menggunakan analisis regresi linier sederhana. Perhitungan pendugaan penurunan muka air tanah masing masing kawasan penggunaan lahan dilakukan dengan menganalisis data tinggi muka air tanah tahun 2001, tahun 2008 dan tahun 2015. Data hasil pengamatan tinggi muka air tanah tahun 2001, 2008 dan 2015 serta hasil analisis regresi terhadap tinggi muka air tanah untuk masing masing kawasan penggunaan lahan disajikan dalam Tabel 2.

Prediksi kedalaman muka air tanah sumur menunjukkan kisaran kedalaman yang bervariasi pada setiap sampel dan pada masing masing kawasan penggunaan lahan. Prediksi Muka air tanah (MAT) terdangkal adalah 7,34 meter terletak di Banjar Batu Belig, Kerobokan Kelod dan muka air tanah (MAT) paling dalam adalah 23,71 meter terdapat di Banjar Padang Tawang desa Canggu. Kedalaman muka air tanah kurang dari 7,8 meter berada di sekitar pantai sampai ketinggian 5 meter diatas permukaan laut. Selanjutnya di bagian tengah rata rata kedalaman muka air tanah sampai 13,5 meter dan paling utara kedalaman muka air tanah mencapai 23,71 meter. Keadaan tinggi muka air tanah di wilayah pesisir Kecamatan Kuta Utara seperti terlihat pada Gambar 4.

Tabel 2 Rata Rata Muka Air Tanah masing masing Kawasan dan Prediksi Tahun 2022

\begin{tabular}{|c|c|c|c|c|c|c|}
\hline No. & $\begin{array}{l}\text { Kawasan } \\
\text { Penggunaan Lahan }\end{array}$ & $\begin{array}{l}\text { MAT } \\
\text { Tahun. } 2001\end{array}$ & $\begin{array}{l}\text { MAT } \\
\text { Tahun. } 2008\end{array}$ & $\begin{array}{l}\text { MAT } \\
\text { Tahun } 2015\end{array}$ & $\begin{array}{l}\text { Rata rata } \\
\text { Penurunan (m) }\end{array}$ & $\begin{array}{l}\text { Prediksi } \\
\text { MAT }\end{array}$ \\
\hline 1 & Akomodasi pariwisata (I) & $-5,20$ & $-6,11$ & $-7,83$ & $-1,90$ & $-9,74$ \\
\hline 2 & Akomodasi pariwisata (II) & $-7,25$ & $-8,60$ & -6.90 & $-2,19$ & $-10,82$ \\
\hline 3 & Sempadan sungai (III) & $-7,22$ & $-8,28$ & -5.90 & $-1,27$ & $-11,26$ \\
\hline 4 & Permukiman (IV) & $-7,09$ & $-8,51$ & $-10,34$ & $-1,55$ & $-11,89$ \\
\hline 5 & Lahan basah (V) & $-6,18$ & $-7,86$ & $-11,08$ & $-2,19$ & $-13,29$ \\
\hline
\end{tabular}

Keterangan :

- MAT = Muka Air Tanah dalam satuan meter 


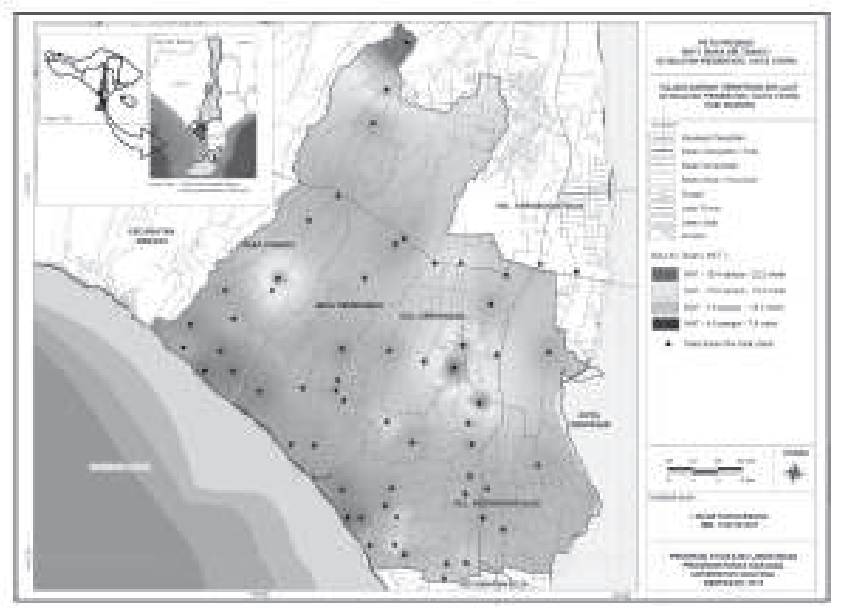

Gambar 4. Prediksi Muka Air Tanah di wilayah Pesisir Kec. Kuta Utara Tahun 2022

\subsection{Prediksi Sebaran Daerah Terintrusi Air Laut}

Prediksi kemungkinan semakin meluasnya intrusi air laut dilakukan dengan menganalisis data kualitas air tanah beberapa parameter yang berpengaruh terhadap intrusi air laut. Data kualitas air tanah dikumpulkan dan diolah dengan menggunakan analisis regresi linier sederhana terhadap beberapa sumur produksi. Selanjutnya hasil analisis data dipetakan untuk mendapatkan peta prediksi Total Zat Padat Terlarut (TDS), peta prediksi Daya Hantar Listrik dan peta prediksi Khlorida. Kemudian masing masing peta tematis dilakukan kompilasi (overlay) untuk menghasilkan peta prediksi intrusi air laut.

Berdasarkan data konsentrasi TDS, $\mathrm{Cl}$ dan DHL air tanah tahun 2001, 2008 dan tahun 2015, maka prediksi tingkat intrusi air laut tahun 2022 tertinggi terjadi pada kawasan akomodasi pariwisata dengan rata rata peningkatan konsentrasi TDS, $\mathrm{Cl}$ dan DHL air tanah sebesar 146,7 mg/l, 14,9 mg/l dan 156,1 $\mu \mathrm{Mhos} / \mathrm{cm}$ yang diakibatkan oleh pengambilan air tanah cukup banyak, jenis tanah regosol coklat kelabu yang memiliki tekstur kasar dan

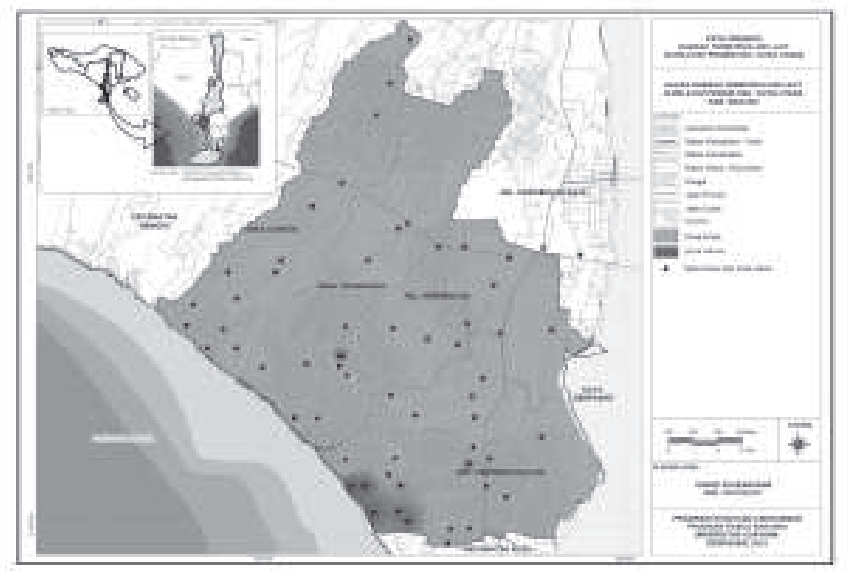

Gambar 5. Prediksi Daerah Terintrusi Air Laut di Pesisir Kec. Kuta Utara Tahun 2022 karakteristik permeabilitas tinggi sehingga mudah meloloskan air tanah. Peta prediksi terintrusi air laut tahun 2022 seperti tersaji pada Gambar 5.

\section{SIMPULAN DAN SARAN}

\subsection{Simpulan}

1. Hasil analisis kualitas air tanah terhadap 60 sampel menunjukkan di wilayah pesisir Kecamatan Kuta Utara telah terjadi penurunan kualitas air tanah sebanyak 14 sampel yaitu Total Dissolved Solid (TDS) tertinggi mencapai $1.122 \mathrm{mg} / \mathrm{l}$, daya hantar listrik tertinggi mencapai $1.677 \mu \mathrm{Mhos} / \mathrm{cm}$ dan khlorida tertinggi mencapai $532,5 \mathrm{mg} / \mathrm{l}$.

2. Peta sebaran daerah teintrusi air laut menunjukkan bahwa di wilayah pesisir Kecamatan Kuta Utara terindikasi rawan intrusi air laut di daerah Petitenget dan Batu Belig, Kelurahan Kerobokan Kelod seluas 78,44 $\mathrm{Ha}$

3. Prediksi tingkat intrusi air laut tahun 2022 tertinggi terjadi pada kawasan akomodasi pariwisata diakibatkan oleh pengambilan air tanah cukup banyak, jenis tanah regosol coklat kelabu yang memiliki tekstur kasar dan karakteristik permeabilitas tinggi sehingga mudah meloloskan air tanah.

\subsection{Saran}

1. Masyarakat maupun pengusaha akomodasi pariwisata diwilayah pesisir Kecamatan Kuta Utara agar melakukan efisiensi penggunaan air tanah, membuat pengimbuhan air tanah buatan dan melakukan daur ulang air limbah serta mengupayakan pengolahan/ desalinasi air laut mnjadi air bersih mengingat kondisi air tanahnya telah mengalami rawan intrusi air laut.

2. Agar pemerintah segera membuat peraturan daerah yang mengatur tentang pengelolaan dan pengendalian pengambilan air tanah serta memfasilitasi pengadaan air bersih melalui jaringan PDAM.

3. Perlu diadakan penelitian lebih lanjut terhadap kualitas air tanah khususnya logam berat yang dapat mempengaruhi kualitas air tanah di Kecamatan Kuta Utara.

\section{DAFTAR PUSTAKA}

Armadi, Ni Made. 2005. Kajian Daerah Intrusi Air laut pada Kawasan Pariwisata Sanur, Kecamatan Denpasar Delatan, Kota Denpasar (tesis) Program Magister Ilmu Lingkungan, Pasca Sarjana Universitas Udayana Denpasar. 
Ashriyati, Hidanafie. 2011. Kajian Kerentanan pada Wilayah terintrusi Air Laut di DKI Jakarta (tesis) Program Pasca Sarjana Ilmu Geografi Universitas Indonesia

Danaryanto, H., Djaendi dan Satriyo Hadipurwo. 2005. Air Tanah di Indonesia dan Pengelolaannya. Departemen Energi dan Sumberdaya Mineral, Ditjen Geologi dan Sumberdaya Mineral.

Djaeni, A. 1982. Peta Hidrogeologi Indonesia. Lembar XI Bali. Dit Geologi dan Tata Lingkungan dan Kawasan Pertambangan. Ditjen Geologi dan Sumberdaya Mineral, Dep. Energi dan Sumberdaya Mineral. Jakarta

Dinas Pendapatan Daerah Kabupaten Badung. 2013. Laporan Pengusaha yang membayar Pajak Hotel dan Restoran di Kabupaten Badung.

Effendi, H. 2003. Telaah Kualitas Air bagi pengelolaan Sumber daya dan Lingkungan Perairan. Yogyakarta. Kanisius.

Fardiaz, S. 1992. Polusi Air dan Udara. Penerbit Kanisius. Yogyakarta.

Hadi Wijoyo 1986. Struktur Geologi Pulau Pulau di Propinsi Bali dan Nusa Tenggara. Badan Geologi. Jakarta
Nurrohim, Ahmad, Tjaturahono, BS. dan Wahyu Setyaningsih. 2012. Kajian Intrusi Air laut di Kawasan Pesisir Kecamatan dan Kabupaten Rembang. Jurusan Geografi, Fakultas Ilmu Sosial, Universitas Negeri Semarang.

Peraturan Daerah Kabupaten Badung Nomor 26 Tahun 2013 tentang Rencana Tata Ruang Wilayah Kabupaten Badung.

Peraturan Gubernur Propinsi Bali No 8 Tahun 2007 tentang Baku Mutu Lingkungan Hidup dan Kriteria baku kerusakan Lingkungan Hidup.

Purwanto. Sudadi 2003. Penentuan Kualitas Air tanah melalui Analisis Unsur Kimia terpilih. Buletin Geologi Tata Lingkungan. Vol. 13 (2) : $81-89$.

Santoso Teguh, Nurul Priyantari dan Puguh Hiskawan . 2013. Pendugaan Intrusi Air Laut dengan Menggunakan Metoda Geolistrik Resistivitas ID di Pantai Payangan, Desa Sumber Rejo Kabupaten Jember. Universitas Jember. 